Article

\title{
Effect of Precious Metals on NO Reduction by CO in Oxidative Conditions
}

\author{
Joudia Akil ${ }^{1}$, Stéphane Siffert ${ }^{1, *(\mathbb{D})}$, Pirault-Roy Laurence ${ }^{2}$, Damien P. Debecker ${ }^{3}$, \\ François Devred ${ }^{3}$, Renaud Cousin ${ }^{1}$ and Christophe Poupin ${ }^{1, * \text { (D) }}$ \\ 1 Unité de Chimie Environnementale et Interactions sur le Vivant, UR 4492, UCEIV, University Littoral Côte \\ d'Opale, 149 Avenue Maurice Schumann, 59140 Dunkerque, France; akil.joudia@gmail.com (J.A.); \\ cousin@univ-littoral.fr (R.C.) \\ 2 Institute of Chemistry of Poitiers, Materials and Natural Resources (IC2MP) UMR-CNRS 7285, University of \\ Poitiers, 4, Rue Michel Brunet (Bât B27), 86073 Poitiers CEDEX, France; laurence.pirault@univ-poitiers.fr \\ 3 Institute of Condensed Matter and Nanosciences (IMCN), Université catholique de Louvain, Place Louis \\ Pasteur, 1, Box L4.01.09, 1348 Louvain la-Neuve, Belgium; damien.debecker@uclouvain.be (D.P.D.); \\ francois.devred@uclouvain.be (F.D.) \\ * Correspondence: siffert@univ-littoral.fr (S.S.); poupin@univ-littoral.fr (C.P.); \\ Tel.: +33-328-658-256 (S.S.); +33-328-237-691 (C.P.)
}

Received: 26 February 2020; Accepted: 23 April 2020; Published: 27 April 2020

\begin{abstract}
Carbon dioxide has become an environmental challenge, where the emissions have reached higher level than can be handled. In this regard, conversion of $\mathrm{CO}_{2}$ to value-added chemicals and thus recycling of $\mathrm{CO}_{2}$ appear a viable option. Prior to valorization, $\mathrm{CO}_{2}$ must be purified. Among several opportunities, oxyfuel combustion is a process in rapid development. However, the gases resulting from this process contain some traces of impurities that can hinder the recovery of $\mathrm{CO}_{2}$ such as $\mathrm{NO}$ and $\mathrm{CO}$. This work has, therefore, focused on the study of the NO-CO reaction in an oxidizing medium, using heterogeneous catalytic materials based on various supported noble metals. These materials were extensively characterized by a variety of methods including Brunauer-Emmett-Teller (BET) surface area measurements, hydrogen chemisorption, transmission electron microscopy (TEM) and $\mathrm{H}_{2}$ temperature programmed reduction $\left(\mathrm{H}_{2}-\mathrm{TPR}\right)$. The results obtained show that the catalytic behavior of $\mathrm{M} / \mathrm{Al}_{2} \mathrm{O}_{3}$ catalysts in $\mathrm{CO}$ oxidation and $\mathrm{NO}$ reduction with $\mathrm{CO}$ in oxidative conditions depends mainly on the nature of the metal. The best result for both reactions is obtained with $\mathrm{Pt} / \mathrm{Al}_{2} \mathrm{O}_{3}$ catalyst. The Pt nanoparticles in their metallic form $\left(\mathrm{Pt}^{\circ}\right)$ as evidenced by TPR could explain the activity.
\end{abstract}

Keywords: environmental chemistry; oxyfuel combustion; NO-CO reaction; heterogeneous catalysis

\section{Introduction}

Greenhouse gas (GHG) emissions generated by human activity has led to an increase in the radiation which is trapped in the atmosphere and induced an increase in the greenhouse effect. This is mainly due to carbon dioxide $\left(\mathrm{CO}_{2}\right)$, representing $79 \%$ of GHGs [1]. The $\mathrm{CO}_{2}$ emitted from anthropic activities is perceived as a constraint in industrial activity resulting in taxes, stringent environmental regulations, and an impact on global warming. To limit these $\mathrm{CO}_{2}$ emissions, it could be considered as a gas with industrial advantages and/or as a new source of carbon for the production of minerals or organic compounds with commercial interest. Reuse of $\mathrm{CO}_{2}$ represents a promising alternative, with important applications in the chemical industry and for power generation.

The processes for the valorization of $\mathrm{CO}_{2}$ can be divided into three different categories: [2]

- $\quad$ Direct use without transformation: industrial use (water treatment, supercritical $\mathrm{CO}_{2} \ldots$ ); 
- Chemical transformation: organic chemical synthesis, methanation, hydrogenation (methanol), reforming: dry $\left(\mathrm{CO}_{2}\right)$ or steam reforming $\left(\mathrm{CO}_{2}+\mathrm{H}_{2} \mathrm{O}\right)$;

- Biological transformation: microalgae, biocatalysis.

However, the $\mathrm{CO}_{2}$ valorization process requires a gas as pure as possible [2].

Oxyfuel-combustion is, therefore, a promising method to obtain a nearly pure $\mathrm{CO}_{2}$ that enables a $\mathrm{CO}_{2}$ rich stream ( $\left.80 \%\right)$ to be obtained [3]. In the oxyfuel system, the combustion flow consists of pure $\mathrm{O}_{2}$ obtained by air distillation. By excluding dinitrogen from the oxidizing flow, the production of NOx is limited as well as the amount of smoke generated. This NOx emission limitation is interesting as NOx are considered as one of the main pollutants of the atmosphere, since they are responsible for a lot of environmental problems like photochemical smog, acid rain, and ozone layer depletion [4]. This process emits also water vapor, unburned components (in function of the waste burned) such as carbon monoxide (generated by incomplete combustion) in addition to nitrogen monoxide [3]. $\mathrm{CO}$ is the cheapest and the most available compound from industrial sources and it could be used as a reductant of $\mathrm{NO}$ although it is known to be one of the worst reductants. P. Malfoy ranked several reducers according the NO half-conversion temperatures achieved using noble metals. The sequence obtained is as follows: $\mathrm{H}_{2}>\mathrm{NH}_{3}>\mathrm{CO}>\mathrm{C}_{3} \mathrm{H}_{5}$ [5]. So it seems possible to purify the $\mathrm{CO}_{2}$ issued from oxyfuel-combustion by the NO-CO reaction which consists of the main challenge that our work tried to address.

In oxyfuel combustion systems, $\mathrm{NO}, \mathrm{CO}, \mathrm{O}_{2}$ are simultaneously present and the following reactions may occur [6]:

$$
\begin{gathered}
2 \mathrm{NO}+2 \mathrm{CO} \rightarrow \mathrm{N}_{2}+2 \mathrm{CO}_{2} \\
2 \mathrm{CO}+\mathrm{O}_{2} \rightarrow 2 \mathrm{CO}_{2}
\end{gathered}
$$

Therefore, as oxygen is present in excess, it competes with $\mathrm{NO}$ for oxidizing the reducing agent (CO) [7]. Due to this effect, many authors studied the competitions between $\mathrm{CO}-\mathrm{NO}$ and $\mathrm{CO}-\mathrm{O}_{2}$ reactions. Shelef et al. demonstrated that the second reaction is predominant over a number of transition metal oxides and supported $\mathrm{Pt}$ [8]. Other authors proved that the $\mathrm{NO}$ addition to $\mathrm{CO}+\mathrm{O}_{2}$ mixture reduces drastically the rate of $\mathrm{CO}_{2}$ formation on Rh catalyst [9] and $\mathrm{Pt}$ supported catalyst [10].

The NO-CO reaction has been widely applied and investigated over various catalysts. For example, three-way catalysts (TWC), composed of noble metals (Rh, $\mathrm{Pd}$ and $\mathrm{Pt}$ ), convert $\mathrm{CO}, \mathrm{NO}$, and hydrocarbons simultaneously [11]. Rh is employed for NO removal because it combines a good activity and selectivity to form nitrogen [12]. On the other hand, $\mathrm{Pt}$ and $\mathrm{Pd}$ ensure the oxidation of $\mathrm{CO}$ and hydrocarbons [13]. Kobylinski and Taylor [14] studied $\mathrm{NO}$ reduction over supported $\mathrm{Pt}, \mathrm{Rh}, \mathrm{Pd}$ and $\mathrm{Ru}$. They proved that, when $\mathrm{CO}$ is used as reducing agent, the reaction over the Ru catalyst is accelerated. The activity sequence of the catalysts was: $\mathrm{Ru}>\mathrm{Rh}>\mathrm{Pt}>\mathrm{Pd}$. Ir was also studied for this reaction in the presence of $\mathrm{O}_{2}[7,15]$. It has been demonstrated that Ir effectively promotes the NO-CO reaction in the presence of an excess of oxygen.

To summarize, the objective is to reduce $\mathrm{NO}$ by $\mathrm{CO}$ in an oxidizing environment with a $\mathrm{CO}_{2}$ rich stream in order to purify the latest without the use of a SCR (selective catalytic reduction) system that would switch to a reductive atmosphere by injecting additives (ammonia or urea) [11]. The important amount of $\mathrm{CO}_{2}$ could be a problem for materials with basic properties due to carbonate species formation. Alumina was then chosen because of its strong Lewis acid centers which ensure the stabilization of species in active state and disperses them adequately, as well as its intrinsic catalytic activity in various reactions $[13,16]$. This paper will present the results obtained by using different precious metals ( $\mathrm{Pt}, \mathrm{Pd}, \mathrm{Rh}, \mathrm{Ru}$ and $\mathrm{Ir}$ ) as catalysts supported on alumina tested for NO-CO reaction. 


\section{Materials and Methods}

\subsection{Catalysts Preparation}

Alumina (Degussa aluminum oxide C) with a specific surface area of $100 \mathrm{~m}^{2} \cdot \mathrm{g}^{-1}$ was used as support. After calcination of support for $4 \mathrm{~h}$ at $500{ }^{\circ} \mathrm{C}$ under air, the catalysts were prepared by wet impregnation of alumina with corresponding nitrous or acetylacetonate (acac) precursors as indicated in the following table (Table 1). For all catalysts, the nominal metallic content was of $1.0 \mathrm{wt} \%$.

Table 1. Metal precursors.

\begin{tabular}{cccccc}
\hline Metal & Iridium & Palladium & Platinum & Rhodium & Ruthenium \\
\hline precursor used & $\operatorname{Ir}(\mathrm{acac})_{3}$ & $\mathrm{Pd}(\mathrm{acac})_{2}$ & $\mathrm{Pt}\left(\mathrm{NO}_{2}\right)_{2}\left(\mathrm{NO}_{3}\right)_{2}$ & $\mathrm{Rh}\left(\mathrm{NO}_{3}\right)_{3}$ & $\mathrm{Ru}(\mathrm{acac})_{3}$ \\
\hline
\end{tabular}

The slurry was shaken at room temperature for $12 \mathrm{~h}$ and after drying in a sand bath at $80{ }^{\circ} \mathrm{C}$, the impregnated alumina was left overnight in an oven at $120^{\circ} \mathrm{C}$. Then, the sample was calcined in dry air $\left(4 \mathrm{~h}, 500^{\circ} \mathrm{C}\right)$ and reduced under pure $\mathrm{H}_{2}$ flow $\left(2 \mathrm{~h}, 500^{\circ} \mathrm{C}\right)$.

\subsection{Characterization of the Catalysts}

Before any impregnation, the support used $\left(\mathrm{Al}_{2} \mathrm{O}_{3}\right)$ was characterized by nitrogen physisorption. The surface area was determined from $\mathrm{N}_{2}$ adsorption/desorption isotherms measured at $-196{ }^{\circ} \mathrm{C}$ with a Brunauer-Emmett-Teller (BET) surface analyzer (Micromeritics Model TRISTAR 3000) using BET and pore size distribution based on Barrett-Joyner-Halenda (BJH) methods. Before the analysis, the samples were outgassed at $250{ }^{\circ} \mathrm{C}$ under vacuum overnight.

The $\mathrm{H}_{2}$ chemisorption capacity was determined by a static volumetric vacuum technique at room temperature, except for $\mathrm{Pd}$ catalyst for which the experiment was run at $70{ }^{\circ} \mathrm{C}$ in order to avoid palladium hydride formation. Firstly, the catalyst was cleaned under ultra-high vacuum overnight to eliminate the adsorbed molecules. Then, the catalyst was reduced under $750 \mathrm{mbar}$ of $\mathrm{H}_{2}$ for $1 \mathrm{~h}$ at $300{ }^{\circ} \mathrm{C}$, and purged under vacuum until reaching a low pressure $\left(p<10^{-5} \mathrm{mbar}\right)$. Two series of hydrogen adsorption isotherms were performed with an increasing hydrogen pressure, from 10 to 70 mbar in steps of 10 mbar. Between the two series, the sample was submitted to ultrahigh vacuum in order to remove weakly bound hydrogen. The adsorbed hydrogen quantity was calculated by extrapolating the isotherm to $p=0$. The first isotherm allows determining the total amount of adsorbed hydrogen and the second one the amount of physisorbed hydrogen. The chemisorbed hydrogen amount was calculated by the difference between the two values for $\mathrm{Ir} / \mathrm{Al}_{2} \mathrm{O}_{3}$ and $\mathrm{Pt} / \mathrm{Al}_{2} \mathrm{O}_{3}$. Concerning the $\mathrm{Rh} / \mathrm{Al}_{2} \mathrm{O}_{3}$ and $\mathrm{Pd} / \mathrm{Al}_{2} \mathrm{O}_{3}$, only the first isotherm was used to determine the amount of adsorbed hydrogen due to a very low $\mathrm{H}_{2}$ physisorption on these materials. The metal particle size was calculated considering a stoichiometry of $\mathrm{H} / \mathrm{M}=1$, and assuming that particles correspond to cubes deposited on the support and exposing 5 faces [17], with an equal distribution between (1 111$)$, (1 110$)$ and (1 00 ) planes.

In order to consolidate the results obtained with hydrogen chemisorption, transmission electron microscopy (TEM) analysis was performed with a JEOL 2100 electron microscope operating at $200 \mathrm{kV}$ with a theoretical resolution of $0.19 \mathrm{~nm}$. Catalysts were finely ground, dispersed in ethanol using an ultrasonic bath and finally deposited on the carbon film of a copper grid. The particle size distribution was estimated on the basis of TEM pictures analysis using ImageJ software and the average particle diameter was determined from the measurement performed on at minimum 100 particles.

$\mathrm{H}_{2}$ temperature programmed reductions (TPR) were performed on a Hiden Catlab equipped with QGA Hiden quadrupole mass spectrometer. The catalysts were first pretreated at $200{ }^{\circ} \mathrm{C}$ for $1 \mathrm{~h}$ under argon (20 mL/min Air Liquide 5.0). The sample was then cooled down to $80{ }^{\circ} \mathrm{C}$ and exposed to a mixture of $0.25 \% \mathrm{H}_{2}$ in an inert atmosphere. The TPR was then carried out using a ramp of $10{ }^{\circ} \mathrm{C} \cdot \mathrm{min}^{-1}$ up to $500{ }^{\circ} \mathrm{C}$. 


\subsection{Catalytic Tests}

Before each test, the catalyst was treated in situ under He flow $\left(40 \mathrm{~mL} \cdot \mathrm{min}^{-1}\right)$ at $200{ }^{\circ} \mathrm{C}$ for $1.5 \mathrm{~h}$. Then, $\mathrm{CO}_{2}$ purification was carried out at atmospheric pressure in a fixed-bed flow reactor containing $150 \mathrm{mg}$ of catalyst (Figure 1). The catalysts were sieved in order to retain grains with diameters between 0.315 and $0.500 \mathrm{~mm}$ and diluted to a constant volume by $\mathrm{SiC}$ (exhibited no activity in $\mathrm{CO}_{2}$ purification from 50 to $500^{\circ} \mathrm{C}$ ) so that all the experiments were carried out under the same conditions $\left(\mathrm{GHSV}=2.2410^{4} \mathrm{~h}^{-1}\right)$.

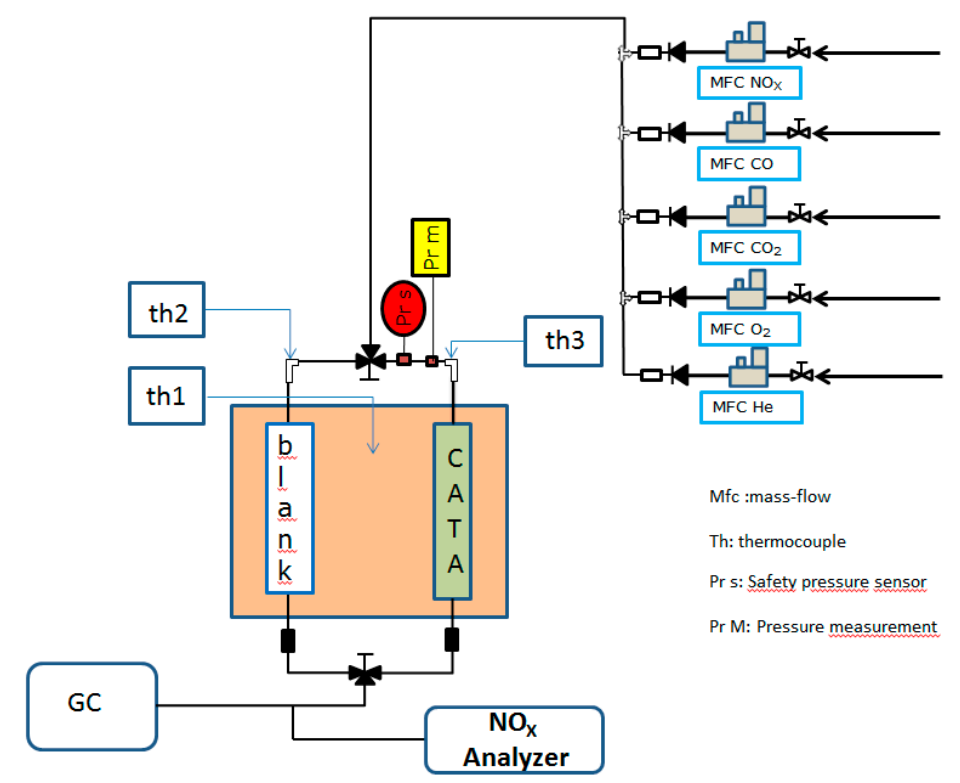

Figure 1. Experimental setup for catalytic purification of $\mathrm{CO}_{2}$ from oxyfuel combustion.

The flow of the reactant gases is composed of: $20 \% \mathrm{CO}_{2}, 10 \% \mathrm{O}_{2}, 0.5 \% \mathrm{CO}$ and $0.02 \% \mathrm{NO}$ (He as eluent gas) with a total flow of $200 \mathrm{~mL} \cdot \mathrm{min}^{-1}$, in the temperature range $50-500{ }^{\circ} \mathrm{C}$. The reaction products $\left(\mathrm{CO}_{2}\right.$ and $\left.\mathrm{N}_{2}\right)$ were analyzed on line by a gas chromatograph (GAS analyzer XXL1300), $\mathrm{NO}$ was analyzed with Xentra $4900 \mathrm{C}$ IR (infrared) analyzer (Servomex). The measurement of $\mathrm{NO}_{2}$ is done indirectly using a $\mathrm{NO}_{2}$ to $\mathrm{NO}$ converter BÜNOx (Bühler Technologies) by comparison.

The conversion, selectivity and yields of the main products are defined in the following way:

- Conversion: $X_{i}(\%)=\frac{n_{i}^{\text {int }}-n_{i}^{\text {out }}}{n_{i}^{\text {int }}} * 100$ where $n_{i}^{\text {int }}$ and $n_{i}^{\text {out }}$ are number of mole of the corresponding compounds " $\mathrm{i}$ " at the inlet and the outlet of the reactor.

- $\quad$ Selectivity: $S_{i}(\%)=\frac{x i n_{i}}{\sum_{i} x_{i n}} * 100$.

- Yield: $Y_{i}(\%)=X_{i} * S_{i} * 100$.

In order to compare the different materials, $\mathrm{T}_{50}$ and $\mathrm{T}_{90}$ factors were taken into account. These factors corresponded, respectively, to the temperature at which $50 \%$ or $90 \%$ of carbon monoxide was converted. For NO reduction, the catalysts were compared according to their maximum efficiency (yield) at total conversion of $\mathrm{CO}$ as the first target is to fully convert $\mathrm{CO}$ in $\mathrm{CO}_{2}$.

\section{Results}

The alumina supported catalysts prepared by wet impregnation with precious metal were studied in the catalytic purification of $\mathrm{CO}_{2}$. In this work, we studied the effect of the nature of the metal in this reaction. 


\subsection{Brunauer-Emmett-Teller (BET) Surface Area}

The specific surface area of the alumina and its pore volume were determined by adsorption of nitrogen. Table 2 summarizes the results obtained by the BET and BJH methods.

Table 2. Specific surface area and porous volume of alumina.

\begin{tabular}{cccc}
\hline Sample & $\mathrm{S}_{\text {BET }}\left(\mathrm{m}^{\mathbf{2}} \cdot \mathrm{g}^{-\mathbf{1}}\right)$ & $\mathrm{V}_{\text {porous }}\left(\mathrm{cm}^{\mathbf{3}} \cdot \mathrm{g}^{\mathbf{- 1}}\right)$ & Average Pore Size $(\mathrm{nm})$ \\
\hline Alumina & 100 & 0.74 & 31 \\
\hline
\end{tabular}

From these results, the alumina used as support for our catalysts is a mesoporous solid with a large specific surface area.

\subsection{Transmission Electron Microscopy (TEM) and $\mathrm{H}_{2}$ Chemisorption}

In order to compare the catalytic activity for our catalysts, we tried to synthesize size-controlled uniform material. We can see in Figure 2 that the synthesized catalytic materials have a quite homogeneous distribution of particle size.
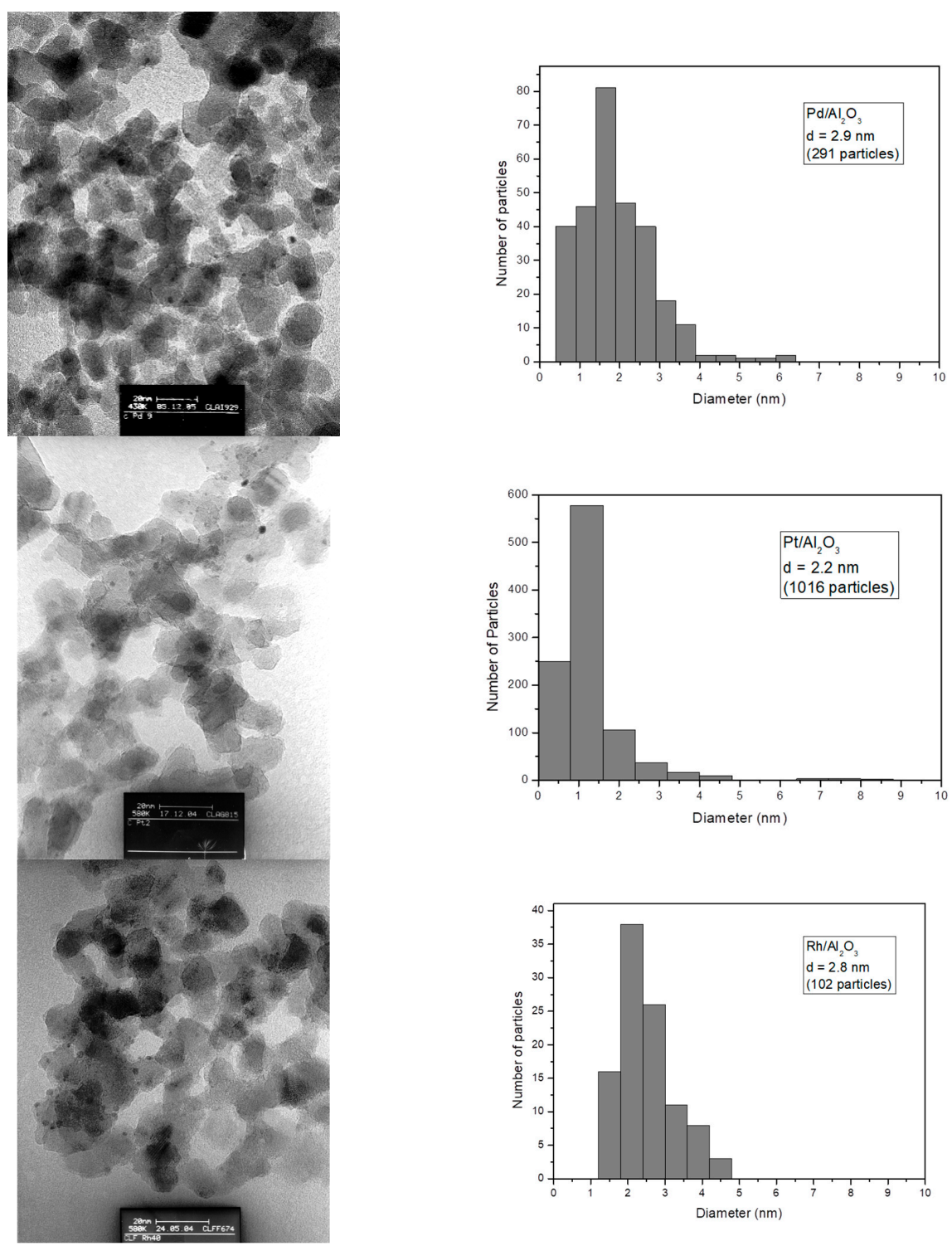

Figure 2. Cont. 

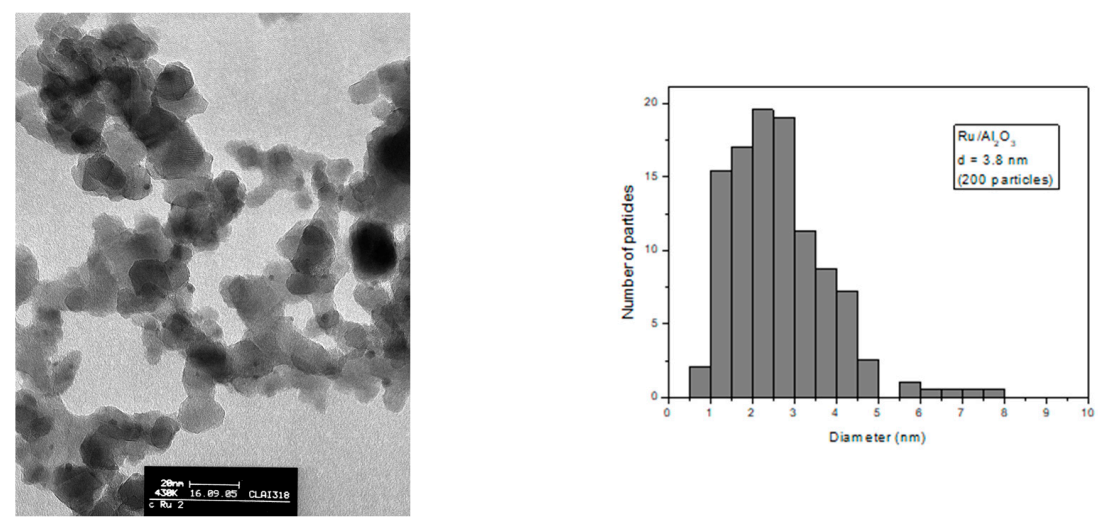

Figure 2. Transmission electron microscope (TEM) pictures and size distribution of the $\mathrm{Al}_{2} \mathrm{O}_{3}$ supported $\mathrm{Pd}, \mathrm{Pt}, \mathrm{Rh}$ and Ru catalysts.

The results obtained by $\mathrm{H}_{2}$ chemisorption reported in Table 3 evidenced that, $\mathrm{Ir}, \mathrm{Pd}, \mathrm{Pt}$ and $\mathrm{Rh}$ on $\mathrm{Al}_{2} \mathrm{O}_{3}$ catalysts presented a similar and small particle size in a narrow window around $2.3 \mathrm{~nm}$. In the case of $\mathrm{Ru} / \mathrm{Al}_{2} \mathrm{O}_{3}$, the particles were larger than those on the other catalyst samples. These results were in accordance with those obtained by TEM.

Table 3. Properties of catalysts: particles size and metallic accessibility.

\begin{tabular}{|c|c|c|c|c|}
\hline Catalysts & Coding & Metallic Accessibility (\%) & $<\mathrm{d}>^{\mathrm{a}}(\mathrm{nm})$ & $<\mathrm{d}>\mathrm{b}(\mathrm{nm})$ \\
\hline $1 \% \operatorname{Ir} / \mathrm{Al}_{2} \mathrm{O}_{3}$ & Ir & 42 & 2.2 & - \\
\hline $1 \% \mathrm{Pd} / \mathrm{Al}_{2} \mathrm{O}_{3}$ & $\mathrm{Pd}$ & 40 & 2.4 & 2.9 \\
\hline $1 \% \mathrm{Pt} / \mathrm{Al}_{2} \mathrm{O}_{3}$ & $\mathrm{Pt}$ & 40 & 2.3 & 2.2 \\
\hline $1 \% \mathrm{Rh} / \mathrm{Al}_{2} \mathrm{O}_{3}$ & $\mathrm{Rh}$ & 41 & 2.2 & 2.8 \\
\hline $1 \% \mathrm{Ru} / \mathrm{Al}_{2} \mathrm{O}_{3}$ & $\mathrm{Ru}$ & 28 & 3.8 & 3.8 \\
\hline
\end{tabular}

\subsection{Temperature Programmed Reduction (TPR) by $\mathrm{H}_{2}$}

The $\mathrm{H}_{2}$-TPR measurements were performed to determine the reduction behaviors and oxidation state of various catalysts as depicted in Figure 3. Since the $\mathrm{Al}_{2} \mathrm{O}_{3}$ support is irreducible from room temperature to $500{ }^{\circ} \mathrm{C}$, the peaks of reduction in this temperature range should correspond to the reduction of the different kinds of metallic active phase species.

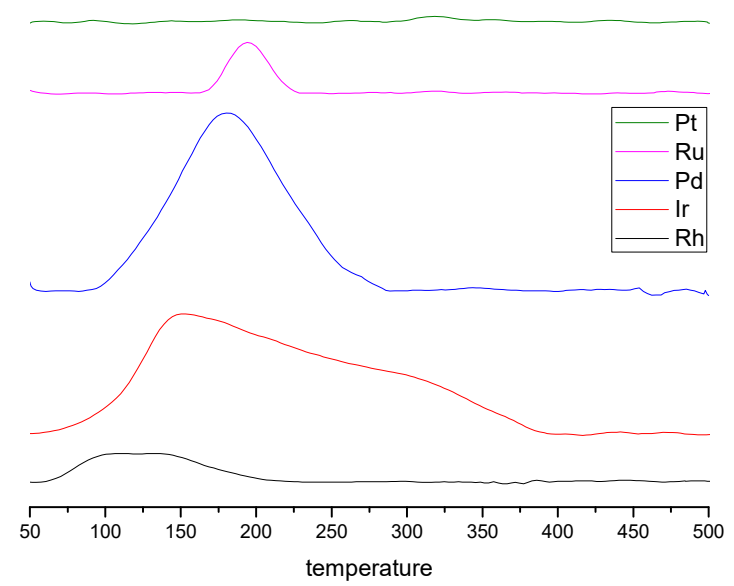

Figure 3. $\mathrm{H}_{2}$-TPR (temperature programmed reduction) patterns of the different catalysts $\left({ }^{\circ} \mathrm{C}\right)$. 
The TPR profile of Pd supported is characterized by one broad pic centered at around $180{ }^{\circ} \mathrm{C}$. According to Ferrer and al. [18] this peak is associated with the reduction of PdOx species that strongly interacts with the support. However, no negative peak was observed at $80{ }^{\circ} \mathrm{C}$ corresponding to the desorption of hydrogen from PdHx which could be formed at low temperature $[16,19]$.

The profile of Ru shows a peak with a maximum at about $194{ }^{\circ} \mathrm{C}$, which is assigned to Ru oxide reduction already demonstrated by Koopman et al. [20].

The $\mathrm{Rh}$ profile is composed of a broad reduction peak from ambient to $250{ }^{\circ} \mathrm{C}$ which is related to the reduction of surface RhOx species, according to the literature [21,22].

The Ir catalyst exhibits a broad reduction peak between $100-400{ }^{\circ} \mathrm{C}$, which can be attributed to the reduction of $\mathrm{IrO}_{2}$ phase $[23,24]$. However, usually the reduction $\mathrm{IrO}_{2}$ phase occurred at higher temperature.

No reduction peak was observed for Pt meaning that Pt nanoparticles should mainly exist in the metallic form $\left(\mathrm{Pt}^{\circ}\right)$ not accessible for further reduction [23].

As all catalysts were reduced at the end of the preparation and stored under air, some metals can be re-oxidized at room temperature either only in the first layers of the particles surface or until to core oxidation, according to their oxidation resistance and their particles size. Checking metals oxidation state before $\mathrm{NO} / \mathrm{CO}$ reaction using TPR technique is therefore of great interest. As expected, $\mathrm{Pd}$ was deeply re-oxidized as the hydrogen consumption evidenced whereas $\mathrm{Rh}$ and $\mathrm{Ru}$ were more lightly re-oxidized during the storage. For Ir, the peak temperature observed is lower than usual suggesting that an unstable oxide is formed probably on the first layers of metallic particles. As it concerns platinum, the lack of reduction peak means that the reduction step went to completion during synthesis and that no re-oxidation occurred under air at room temperature or so weakly that the Ar treatment before TPR can remove the oxygen [23].

M. Haneda et al. [25] have shown that NO reduction by CO occurs on stable iridium metal sites. We can therefore assume that the more metallic the species is, the better the activity will be for the reaction studied. Thus, a good platinum activity is expected.

\subsection{Catalytic Reaction}

The catalytic performances of different materials were studied and determined for the catalytic total $\mathrm{CO}$ oxidation and $\mathrm{NO}$ reduction with $\mathrm{CO}$ in oxidizing atmosphere $\left(10 \% \mathrm{O}_{2}\right)$ and $\mathrm{CO}_{2}$ rich stream under identical conditions.

Light-off curve of support $\left(\mathrm{Al}_{2} \mathrm{O}_{3}\right)$ and $\mathrm{NO}$ reduction or oxidation yield were determined and are reported in Figure 4.

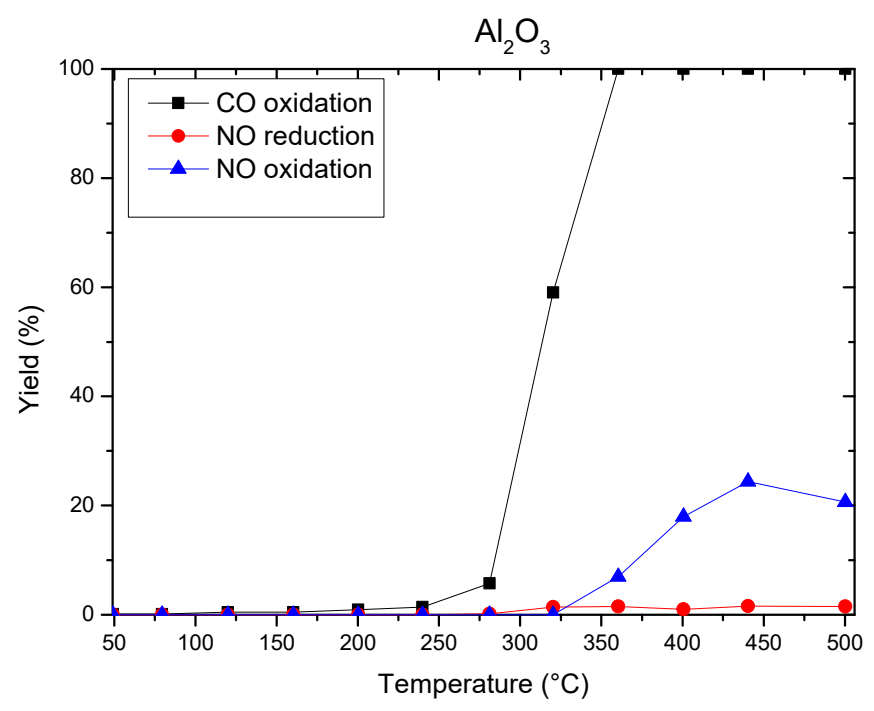

Figure 4. Light-off curves for $\mathrm{Al}_{2} \mathrm{O}_{3}$ support and $\mathrm{NO}$ reduction or oxidation yield. 
It can thus be seen in Figure 4 that on the alumina it is possible to have a complete oxidation of the $\mathrm{CO}$. For the conversion of $\mathrm{NO}$, there is a slight oxidation of $\mathrm{NO}$ at very high temperature but no reduction. No activity was observed with an empty reactor.

Figure 5 shows the activities of the catalysts for $\mathrm{CO}$ oxidation. They exhibit the activity for this reaction at the temperatures higher than $100{ }^{\circ} \mathrm{C}$ and the conversion increases with the reaction temperature. For all tests, catalytic performances were compared by considering $\mathrm{T}_{50}$ and $\mathrm{T}_{90}$ for $\mathrm{CO}$ oxidation (Table 4), which respectively corresponded to the temperatures at which $50 \%$ and $90 \%$ of CO were converted. The results obtained are illustrated in Figure 5. The conversion of $\mathrm{CO}$ to $\mathrm{CO}_{2}$ reached $100 \%$ for all studied catalysts. Ir and Rh have similar activity values with $\mathrm{T}_{50}$ at $236^{\circ} \mathrm{C}$. The general order of catalytic activity, based on the temperature required for $50 \%$ conversion $\left(\mathrm{T}_{50}\right)$, is the following: $\mathrm{Pt}>\mathrm{Pd}>\mathrm{Ir} \sim \mathrm{Rh}>\mathrm{Ru}$.

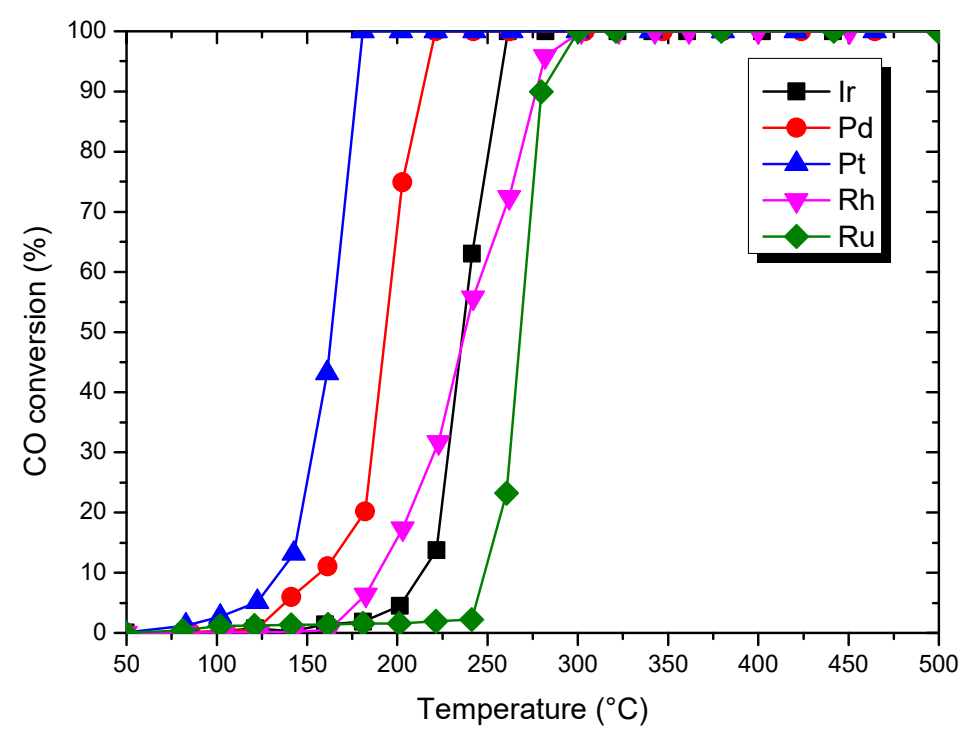

Figure 5. Light-off curves of $\mathrm{CO}$ conversion for the different materials. Feedstream composition: $0.02 \%$ $\mathrm{NO}, 0.5 \% \mathrm{CO}, 10 \% \mathrm{O}_{2}$ and $20 \% \mathrm{CO}_{2}$, and balance He. Space velocity: $2.2410^{4} \mathrm{~h}^{-1}$.

Table 4. $\mathrm{T}_{50}$ and $\mathrm{T}_{90}$ of catalysts' catalytic $\mathrm{CO}$ oxidation.

\begin{tabular}{ccc}
\hline Catalysts & $\mathbf{T}_{\mathbf{5 0}}\left({ }^{\circ} \mathbf{C}\right)$ & $\mathbf{T}_{\mathbf{9 0}}\left({ }^{\circ} \mathbf{C}\right)$ \\
\hline $\mathrm{Ir}$ & 236 & 260 \\
\hline $\mathrm{Pd}$ & 194 & 212 \\
\hline $\mathrm{Pt}$ & 164 & 176 \\
\hline $\mathrm{Rh}$ & 236 & 280 \\
\hline $\mathrm{Ru}$ & 268 & 280 \\
\hline
\end{tabular}

Considering $\mathrm{T}_{90}, \mathrm{Pt}$ shows the better performance $\left(176^{\circ} \mathrm{C}\right)$, Rh and Ru present similar activity values with $280^{\circ} \mathrm{C}$. The ranking for catalysts does not much change to that obtained at $\mathrm{T}_{50}: \mathrm{Pt}>\mathrm{Pd}>$ $\mathrm{Ir}>\mathrm{Rh} \sim \mathrm{Ru}$. The oxidation of $\mathrm{CO}$ was investigated on noble metal catalysts supported on $\mathrm{TiO}_{2}$ by V.P. Santos et al. [26] and they pointed out on metallic particles between $2-4 \mathrm{~nm}$ the same activity order: $\mathrm{Pt}>\mathrm{Pd}>\mathrm{Ir}>\mathrm{Rh}$.

The oxidation of $\mathrm{CO}$, reduction of $\mathrm{NO}$ and oxidation of $\mathrm{NO}$ over the impregnated $\mathrm{Al}_{2} \mathrm{O}_{3}$ with $\mathrm{Ir}$, $\mathrm{Pd}, \mathrm{Pt}, \mathrm{Rh}, \mathrm{Ru}$ were evaluated, and the results obtained are reported in Figure 6. 


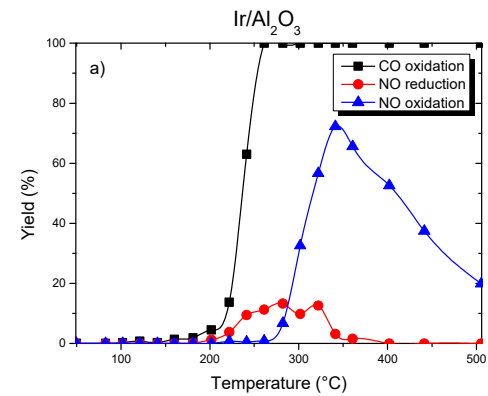

(a)

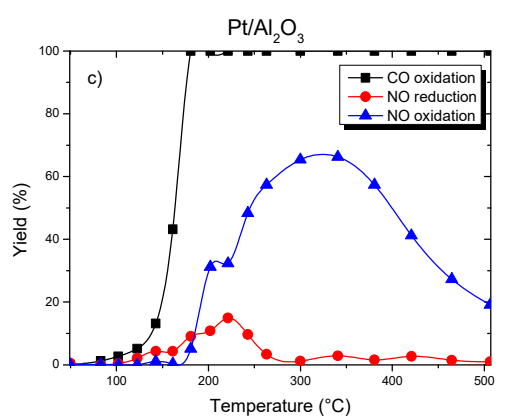

(c)

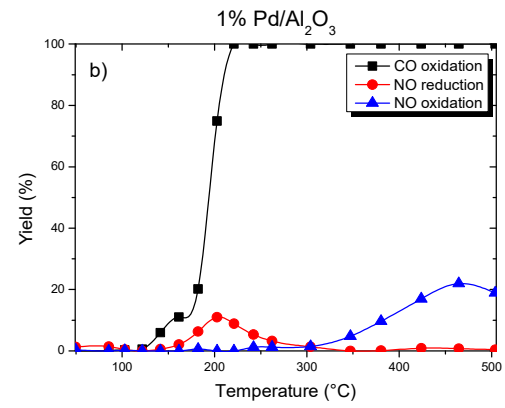

(b)

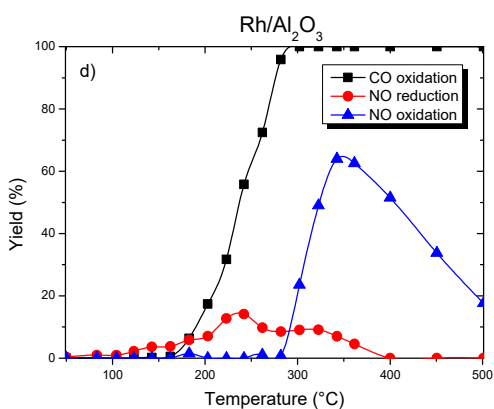

(d)

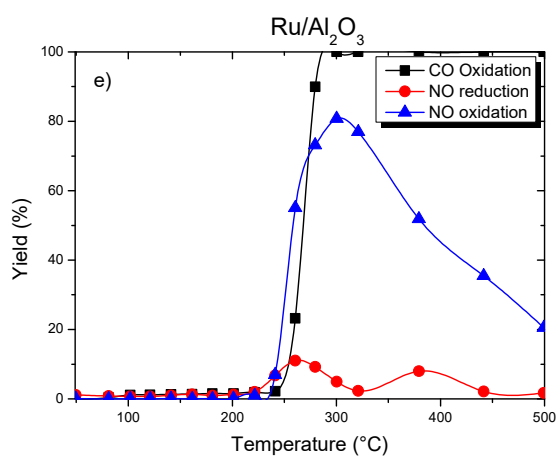

(e)

Figure 6. Catalytic activity for the (a) $\mathrm{Ir},(\mathbf{b}) \mathrm{Pd},(\mathbf{c}) \mathrm{Pt},(\mathrm{d}) \mathrm{Rh},(\mathbf{e}) \mathrm{Ru}$, catalysts supported on alumina. Feedstream composition: $0.02 \% \mathrm{NO}, 0.5 \% \mathrm{CO}, 10 \% \mathrm{O}_{2}$ and $20 \% \mathrm{CO}_{2}$, and balance He. Space velocity: $2.24 \cdot 10^{4} \mathrm{~h}^{-1}$

$\mathrm{CO}$ is completely oxidized at $260{ }^{\circ} \mathrm{C}$ with a $13 \%$ of $\mathrm{NO}$ reduction on $\mathrm{Ir} / \mathrm{Al}_{2} \mathrm{O}_{3}$ (Figure 6a). The oxidation of $\mathrm{NO}$ reached $72.3 \%$ at $340{ }^{\circ} \mathrm{C}$.

$\mathrm{Pd}$ activity in $\mathrm{CO}$ and $\mathrm{NO}$ reactions (Figure $6 \mathrm{~b}$ ) showed that the oxidation of $\mathrm{CO}$ is carried out at $220^{\circ} \mathrm{C}$. NO reduction reached a maximum with $11 \%$ at $200{ }^{\circ} \mathrm{C}$.

When using Pt catalyst, $\mathrm{CO}$ was totally oxidized at $180^{\circ} \mathrm{C}$ (Figure $6 \mathrm{c}$ ). NO reduction began from the start of $\mathrm{CO}$ oxidation. $\mathrm{Pt} / \mathrm{Al}_{2} \mathrm{O}_{3}$ reduced the $\mathrm{NO}$ from $140{ }^{\circ} \mathrm{C}$ to $300{ }^{\circ} \mathrm{C}$ with a maximum reduction $(14.9 \%)$ at $220^{\circ} \mathrm{C}$, and the oxidation phase was also bell-shaped with an optimum $(66.2 \%)$ at $340{ }^{\circ} \mathrm{C}$.

$\mathrm{CO}$ oxidation on supported Rh catalyst (Figure 6d) occurred at higher temperature than with $\mathrm{Pt}$ or $\mathrm{Pd}$ ones, and the total conversion of $\mathrm{CO}$ was only obtained at $300^{\circ} \mathrm{C}$. This was in full agreement with 
the literature on three-way catalysts that use Rh to convert NOx [12]. With regard to NO conversion, the reduction of $\mathrm{NO}$ was $14.4 \%$ at $240{ }^{\circ} \mathrm{C}$. On the other hand, at $340{ }^{\circ} \mathrm{C}, \mathrm{NO}$ was oxidized at $64.2 \%$.

Similarly to $\mathrm{Rh}$, the total conversion of $\mathrm{CO}$ on $\mathrm{Ru} / \mathrm{Al}_{2} \mathrm{O}_{3}$ catalysts (Figure $6 \mathrm{e}$ ) was obtained at $300^{\circ} \mathrm{C}$ and the NO conversion reached $85 \%$ including $80 \%$ for its oxidation and only $5 \%$ for its reduction.

In order to compare and highlight the influence of noble metals on the NO reduction with $\mathrm{CO}$ in oxidative conditions, Figure 7 displays the maxima of $\mathrm{NO}$ reduction at total oxidation of $\mathrm{CO}$ over all catalysts. The $\mathrm{Pt} / \mathrm{Al}_{2} \mathrm{O}_{3}$ and $\mathrm{Ir} / \mathrm{Al}_{2} \mathrm{O}_{3}$ catalysts exhibited the best performances for $\mathrm{NO}$ reduction by $\mathrm{CO}$ in the presence of an excess of oxygen and $\mathrm{CO}_{2}$ rich stream. Pd, $\mathrm{Rh}$ and $\mathrm{Ru}$ led to lower activity than $\mathrm{Pt}$ and Ir. The yield for $\mathrm{NO}$ reduction was similar on these catalysts but at different temperatures: $220^{\circ} \mathrm{C}$ for Pd, $320^{\circ} \mathrm{C}$ for Rh and $380{ }^{\circ} \mathrm{C}$ for Ru.

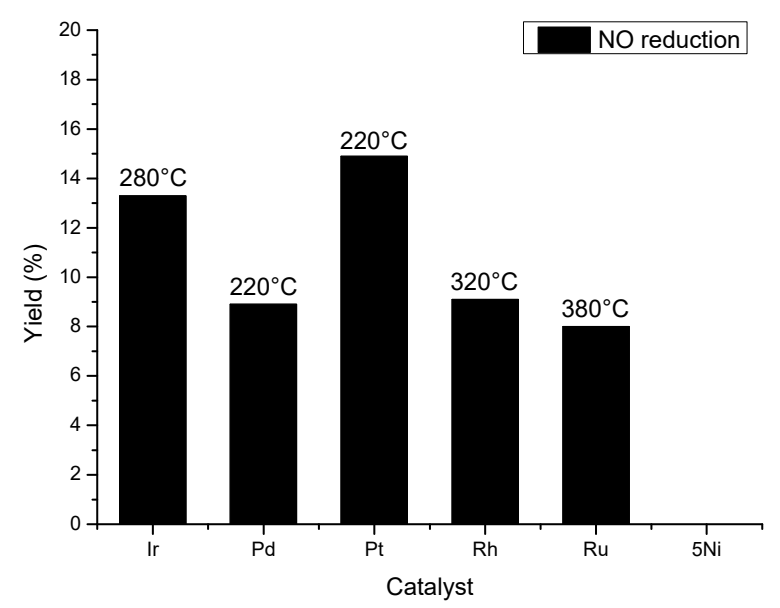

Figure 7. $\mathrm{NO}$ reduction at total oxidation of $\mathrm{CO}$. Feedstream composition: $0.02 \% \mathrm{NO}, 0.5 \% \mathrm{CO}, 10 \% \mathrm{O}_{2}$ and $20 \% \mathrm{CO}_{2}$, and balance He. Space velocity: $2.2410^{4} \mathrm{~h}^{-1}$.

In our results, the low activity of the Pd compared to Ir catalyst could be explained by an oxygen poisoning of the Pd. Almusaiteer and Chuang [27] proved that the presence of $\mathrm{O}_{2}$ in NO-CO reaction flow plays a role of poison on $\mathrm{Pd} / \mathrm{Al}_{2} \mathrm{O}_{3}$ catalyst. The adsorbed oxygen inhibits $\mathrm{N}-\mathrm{O}$ dissociation thus causing an accumulation of $\mathrm{Pd}-\mathrm{N}=\mathrm{O}$ and diminution of conversion of $\mathrm{NO}$. On the other hand, Ir has a superior ability over other precious metals to convert $\mathrm{NO}$ under oxidizing environment due to its ability to adsorb NO dissociatively in the presence of an excess of $\mathrm{O}_{2}$ [15]. Tauster and Murell [7] confirmed this result and they proved that $\mathrm{Ir}$ is the only catalyst favoring the NO-CO reaction over $\mathrm{CO}-\mathrm{O}_{2}$. The results reported in Figure 7 evidenced that $\mathrm{Ir} / \mathrm{Al}_{2} \mathrm{O}_{3}$ activity is certainly interesting but $\mathrm{Pt} / \mathrm{Al}_{2} \mathrm{O}_{3}$ exhibits the higher activity for reducing $\mathrm{NO}$ by $\mathrm{CO}$ in an oxidizing environment. Moreover, this interesting performance occurs at a lower temperature than those of the other catalysts. The better performances of Pt and to a lesser extent Ir could be correlated with the TPR results where Pt and Ir were shown to be less oxidized than the other catalysts. As expected, the more metallic the species is and remains, the better the activity for $\mathrm{NO}$ reduction is despite these oxidizing operating conditions.

\section{Conclusions}

This work deals with the identification of the best metal catalysts for $\mathrm{CO}_{2}$ purification in oxidative conditions. In this work, we focus on the NO reduction on alumina supported precious metals using carbon monoxide as reducing agent in oxidizing conditions. First of all, it is possible to achieve the reduction of the $\mathrm{NO}$ in an oxidizing medium with a catalytic material by using $\mathrm{CO}$, one of the worst reducers, but nevertheless always present in the industrial process outputs. The better performances for $\mathrm{NO}$ reduction were obtained for $\mathrm{Pt} / \mathrm{Al}_{2} \mathrm{O}_{3}$ catalyst for which the metallic state of particles was evidenced in TPR. The results clearly demonstrated that the more metallic the species is and remains, the better the activity for $\mathrm{NO}$ reduction despite these oxidizing operating conditions. The work is still in progress but it has already proven that the $\mathrm{NO} / \mathrm{CO}$ reaction can be achieved without injection of 
additional reducers such as ammonia, which can facilitate the implementation of the process and lower the operating cost.

Author Contributions: J.A. prepared the materials, conducted the experiments and wrote the first draft of the paper. C.P. and S.S. supervised the work. D.P.D. and F.D. realized the TPR measurements. P.-R.L. managed $\mathrm{H}_{2}$ chemisorption and TEM analysis. J.A., D.P.D., F.D., P.-R.L., R.C., C.P. and S.S. contributed to the data interpretation, the discussion and the revision of the paper. All authors have read and agreed to the published version of the manuscript.

Funding: This research was funded by: Innocold, Dunkerque LNG, Greater Dunkirk Council and ULCO.

Conflicts of Interest: The authors declare no conflict of interest.

\section{References}

1. Olivier, J.G.J.; Schure, K.M.; Peters, J.A.H.W. Trends in Global CO2 and Total Greenhouse Gas Emissions: Summary of the 2017 Report; PBL Netherlands Environmental Assessment Agency: The Hague, The Netherlands, 2017.

2. Dumergues, L.; Favier, B.; Claver, R.A. CO2 Reuse. State of the Art and Expert Opinion Case of Waste Treatment Activities; RECORD: Pau, France, 2014.

3. Iloeje, C.; Field, R.; Ghoniem, A.F. Modeling and parametric analysis of nitrogen and sulfur oxide removal from oxy-combustion flue gas using a single column absorber. Fuel 2015, 160, 178-188. [CrossRef]

4. Skalska, K.; Miller, J.S.; Ledakowicz, S. Trends in NOx abatement: A review. Sci. Total. Environ. 2010, 408, 3976-3989. [CrossRef] [PubMed]

5. Malfoy, P. Reduction Catalytique de $\mathrm{NO}$ et $\mathrm{N}_{2} \mathrm{O}$ par $\mathrm{H}_{2}, \mathrm{CO}$ ou C3H8; University of Poitiers: Poitiers, France, 1997.

6. Hegedus, L.L.; Hertz, R.K.; Oh, S.H.; Aris, R.J. Effect of catalyst reactions loading on the simultaneous of NO, $\mathrm{CO}$, and $\mathrm{O}_{2}$. J. Catal. 1979, 57, 513-515. [CrossRef]

7. Tauster, S.; Murrell, L. The NO-CO reaction in the presence of excess $\mathrm{O}_{2}$ as catalyzed by iridium. J. Catal. 1976, 41, 192-195. [CrossRef]

8. Shelef, $\mathrm{M}$. The oxidation of $\mathrm{CO}$ by $\mathrm{O}_{2}$ and by $\mathrm{NO}$ on supported chromium oxide and other metal oxide catalysts. J. Catal. 1968, 12, 361-375. [CrossRef]

9. Oh, S. Role of NO in inhibiting CO oxidation over alumina-supported rhodium. J. Catal. 1986, 101, 114-122. [CrossRef]

10. Voltz, S.E.; Morgan, C.R.; Liederman, D.; Jacob, S.M. Kinetic study of carbon monoxide and propylene oxidation on platinum catalysts. Ind. Eng. Chem. Prod. Res. Dev. 1973, 12, 294-301. [CrossRef]

11. Granger, P.; Parvulescu, V. Catalytic NOxAbatement systems for mobile sources: From three-way to lean burn after-treatment technologies. Chem. Rev. 2011, 111, 3155-3207. [CrossRef]

12. Barbier, J.; Duprez, D. Steam effects in 3-way catalysis. Appl. Catal. B 1994, 4, 105-140. [CrossRef]

13. Vedyagin, A.A.; Volodin, A.M.; Stoyanovskii, V.; Kenzhin, R.M.; Slavinskaya, E.; Mishakov, I.V.; Plyusnin, P.E.; Shubin, Y.V. Stabilization of active sites in alloyed Pd-Rh catalysts on $\gamma-\mathrm{Al}_{2} \mathrm{O}_{3}$ support. Catal. Today 2014, 238, 80-86. [CrossRef]

14. Kobylinski, T.P.; Taylor, B.W. The catalytic chemistry of nitric oxide. J. Catal. 1974, 33, 376-384. [CrossRef]

15. Taylor, K.C.; Schlatter, J.C. Selective reduction of nitric oxide over noble metals. J. Catal. 1980, 63, 53-71. [CrossRef]

16. Wang, C.-B.; Lee, H.-G.; Yeh, T.-F.; Hsu, S.-N.; Chu, K.-S. Thermal characterization of titania-modified alumina-supported palladium and catalytic properties for methane combustion. Thermochim. Acta 2003, 401, 209-216. [CrossRef]

17. Bond, G.C. The origins of particle size effects in heterogenous catalysis. Surf. Sci. 1985, 156, 966-981. [CrossRef]

18. Ferrer, V.; Finol, D.; Solano, R.; Moronta, A.; Ramos, M. Reduction of NO by CO using Pd-CeTb and Pd-CeZr catalysts supported on $\mathrm{SiO}_{2}$ and $\mathrm{La}_{2} \mathrm{O}_{3}-\mathrm{Al}_{2} \mathrm{O}_{3}$. J. Environ. Sci. 2015, 27, 87-96. [CrossRef] [PubMed]

19. Hosseini, M. Etude de Catalyseurs Pd/Au Déposés Sur Oxydes Poreux, $\mathrm{TiO}_{2}$ et Composés Organiques Volatils (COV); Littoral University: Dunkerque, France, 2008.

20. Koopman, P. Characterization of ruthenium catalysts as studied by temperature programmed reduction. J. Catal. 1981, 69, 172-179. [CrossRef]

21. Zhao, B.; Ran, R.; Cao, Y.; Wu, X.; Weng, D.; Fan, J.; Wu, X. Insight into the effects of different ageing protocols on Rh/Al2O3 catalyst. Appl. Surf. Sci. 2014, 308, 230-236. [CrossRef] 
22. McCabe, R.; Usmen, R.; Ober, K.; Gandhi, H. The Effect of alumina phase-structure on the dispersion of rhodium/alumina catalysts. J. Catal. 1995, 151, 385-393. [CrossRef]

23. Goula, M.; Charisiou, N.; Papageridis, K.; Delimitis, A.; Papista, E.; Pachatouridou, E.; Iliopoulou, E.; Marnellos, G.; Konsolakis, M.; Yentekakis, I.V. A comparative study of the $\mathrm{H}_{2}$-assisted selective catalytic reduction of nitric oxide by propene over noble metal (Pt, Pd, Ir) $/ \gamma-\mathrm{Al}_{2} \mathrm{O}_{3}$ catalysts. J. Environ. Chem. Eng. 2016, 4, 1629-1641. [CrossRef]

24. Vicerich, M.A.; Benitez, V.M.; Especel, C.; Epron, F.; Pieck, C. Influence of iridium content on the behavior of $\mathrm{Pt}-\mathrm{Ir} / \mathrm{Al}_{2} \mathrm{O}_{3}$ and $\mathrm{Pt}-\mathrm{Ir} / \mathrm{TiO}_{2}$ catalysts for selective ring opening of naphthenes. Appl. Catal. A Gen. 2013, 453, 167-174. [CrossRef]

25. Haneda, M.; Fujitani, T.; Hamada, H. Effect of iridium dispersion on the catalytic activity of $\mathrm{Ir} / \mathrm{SiO}_{2}$ for the selective reduction of $\mathrm{NO}$ with $\mathrm{CO}$ in the presence of $\mathrm{O}_{2}$ and $\mathrm{SO}_{2}$. J. Mol. Catal. A Chem. 2006, 256, 143-148. [CrossRef]

26. Santos, V.P.; Carabineiro, S.A.C.; Tavares, P.B.; Pereira, M.F.R.; Órfão, J.J.M.; Figueiredo, J.L. Oxidation of CO, ethanol and toluene over $\mathrm{TiO}_{2}$ supported noble metal catalysts. Appl. Catal. B 2010, 99, 198-205. [CrossRef]

27. Almusaiteer, K.; Chuang, S.S. Isolation of active adsorbates for the NO-CO Reaction on $\mathrm{Pd} / \mathrm{Al}_{2} \mathrm{O}_{3}$ by selective enhancement and selective poisoning. J. Catal. 1998, 180, 161-170. [CrossRef]

(C) 2020 by the authors. Licensee MDPI, Basel, Switzerland. This article is an open access article distributed under the terms and conditions of the Creative Commons Attribution (CC BY) license (http://creativecommons.org/licenses/by/4.0/). 